\title{
Monitoring, Analysis, and Management of Network Public Opinion: Status and Challenges
}

\author{
Yang Shanlin ${ }^{1}$, Zhou Bin², Jia Yan², Huang Jiuming ${ }^{2}$ \\ 1. Hefei University of Technology, Hefei 230009, China \\ 2. National University of Defense Technology, Changsha 410073, China
}

\begin{abstract}
From the perspectives of management and sociology, computer science, and information technology, this paper summarizes the research on domestic and international network public opinion monitoring, analysis, and management, followed by a brief introduction of major industrial applications in China. Based on this, the author discusses the future development of network public opinion in the face of challenges and opportunities in the era of big data.
\end{abstract}

Keywords: network public opinion; monitoring; analysis; management

\section{Introduction}

A report from the China Internet Network Information Center (CNNIC) indicates that in June 2016, the number of Internet users in China totaled 710 million and the Internet penetration rate was $51.7 \%$ [1]. With the increasing spread of the Internet and its applications in people's daily lives, users are more likely to express their viewpoints about real-life events through microblogs, forums, WeChat, and other interactive network applications. At the same time, social changes and economic reforms make social life more diversified and complex, and social contradictions and mass emergencies have become multiple trends. The Internet has become an important place where social contradictions and events are bred, developed, and evolved. Recently, "South China Sea Arbitration," "Qingdao's high prawn bill," "Chai Jing's 'Under the Dome'," "Tianjin Port Explosion," "Tu Youyou's Nobel Prize," "the divorce of Actor Wang Baoqiang," and other political, economic, cultural, and entertainment events have contributed towards forming network public opinion. This demonstrates the enormous energy of the Internet as a new diffusion channel and medium, and promotes the evolution of the event itself. In addition, opinion can influence the real world, affecting the development of the event.

Generally, network public opinion extends and reflects reallife problems in the virtual network, which is the sum of all the cognitive, attitudinal, emotional, and behavioral tendencies of people. Its production and dissemination platforms usually include network news, forums, blogs, microblogs, instant messaging, online surveys, network signatures, and e-mail. In recent years, the popularization of mobile Internet and intelligent terminals have strengthened the socialization and mobile features of network public opinion communication, making network public opinion more involved in the process of generation and communication. Furthermore, during this process, communication becomes more interactive, and information dissemination becomes faster, bringing great challenges for network public opinion monitoring, analysis, and management. However, with the development of computer science, network technique, network technology, big data analysis technology, social psychology, and social management, new theories and methods provide new choices for the tasks involved in network public opinion monitoring, analysis, and management.

Received date: 21 October 2016; revised date: 14 November 2016

Corresponding author: Yang Shanlin, Chinese Academy of Engineering, Academician. Major research fields include management science and information systems. E-mail: yangsl@hfut.edu.cn.

Funding program: CAE Major Advisory Project "Research on Cyberspace Security Strategy” (2015-ZD-10).

Chinese version: Strategic Study of CAE 2016, 18 (6): 017-022

Cited item: Yang Shanlin et al. Monitoring, Analysis, and Management of Network Public Opinion: Status and Challenges. Strategic Study of CAE, http://10.15302/ J-SSCAE-2016.06.004 


\section{Overview of research and application}

Network public opinion monitoring, analysis, and management are cross-disciplinary, spanning computer science, management, sociology, communication, psychology, and other disciplines, and successfully attracting the attention of researchers in these domains. This paper reviews the status of domestic and international research from the perspectives of management and sociology as well as computer science and information technology.

\subsection{Perspective of management and sociology}

From the perspective of management and sociology researchers, cyberspace is a specific public space shared by all netizens. Network public opinion management has become a focus of public management and social management research. Related work can be summarized as research on online public polling and online public opinion. The former studies the methods and technologies of opinion surveys, basic theories on popular will, and the relation between politics (such as elections) and foreign policy. The latter focuses on the concept and theory of network public opinion, public opinion strategy of specific events (such as war events), and public opinion and crisis management [2].

From a more international viewpoint, research can be summarized as three aspects, namely public opinion attributes, network public opinion influence, and network public opinion management: (1) Regarding the aspect of network public opinion attributes, studies focus on the effect of network interaction on public opinion transmission, supervision, and management, and analyze the causes of network public opinion formation and the polarization process of opinion. For example, Sunstein used group polarization theory to analyze 60 influential government websites, finding that the views of group leaders had a polarization effect [3]. (2) Regarding the aspect of network public opinion influence, through various methods, researchers have investigated the ways and mechanisms of the influence of public opinion in political, economic, and social fields, amongst others. For example, the results of a study by Bond on the effect of political mobilization on the electorate in the 2010 U.S. congressional election were published in Nature in September 2012 [4]. In addition, Kuhnen et al. studied the impact of network public opinion on the pay structure and quantity of management [5]. (3) Regarding the aspect of network public opinion management, the current representative management model used in international studies is as follows. First, improve laws and regulations to achieve legislative control and effectively manage network content. Second, develop and implement various constraints of cyberspace to guide the public to visit the network. Third, establish civil institutions to actively guide and encourage network media and the self-discipline of network users. Fourth, use technical means to implement national or government control and filter the network [6].
The work on domestic network public opinion research is related to emergencies and government governance [7,8]. In recent years, local scholars studied China's national conditions from various perspectives such as monitoring and analysis of network public opinion, situation analysis and response, and early warnings of crises. For monitoring and analysis, researchers obtained results on aspects including the formation of network public opinion [9], characteristics of topic transmission [10-12], topic evolution [13-15], emotional evolution [16], group effects $[17,18]$, influence analysis $[19,20]$, environmental incentive analysis [21,22], and simulation [23,24]. Regarding situation analysis, scholars investigated the risk evaluation index system [25] or the index system applicable to a specific domain. Finally, for response, guidance, and control, guide strategy [26], the reacting method [27], and governance mode [28] were key areas of focus, and the models and methods employed in forecasting and predicting crisis events were studied [29]. In addition, regarding the application of research efforts, domestic research covered university education, government decision-making, group events, food safety, and business management [30].

\subsection{Perspective of computer science and information technology}

From the perspective of the scholars in computer science and information technology, network public opinion monitoring, analysis, and management focuses on the use of computer technology and information processing technology during the process. These technologies include search engines, natural language processing, social network analysis, machine learning, and information retrieval. Meanwhile, by employing monitoring and analysis tools, public events and opinions can be automatically determined and analyzed for generation, dissemination, or evolution patterns.

The procedure of the monitoring and analysis of network public opinion includes data collection and preprocessing, emergency or hot topic detection, intelligent clustering classification, topic detection and tracking, tendency analysis, and public opinion reporting. In addition, for some network public opinion management tasks, public opinion briefings and public opinion special reports are also included to provide analysis data for effective decision-making related to understanding public opinion dynamics.

Currently, more than 100 types of network public opinion analysis systems have been developed that serve in various domains [6]. These systems have functions such as gathering, preprocessing, monitoring, providing early warnings, analysis, guidance, displays, and generating public opinion reports. According to pre-configured information gathering rules, the gathering function collects data from various sources with the help of a distributed parallel program (also known as a web crawler), and organizes and aggregates the scattered data. The preprocessing function is used to standardize and integrate incomplete 
and/or inconsistent data and data transformation, which can ease data analysis and processing. The monitoring function monitors network data for specific events or emergencies in a timeline-driven mode, while the early warning function works with these monitoring functions, setting alarms to detect specific events or emergencies. Furthermore, in accordance with public opinion, the function can include an early warning alert, sending warning messages to ensure the appropriate handling of crises. The analysis function selects appropriate tools and applies statistical methods, natural language processing, machine learning, and neural network technologies to obtain results. The display function displays the results in the form of a report, graph, and other type of visualization, which is presented to the user. The guide function tries to influence information propagation, using social networks, forums, blogs, microblogs, and other channels to automatically deliver information. Finally, the report generation function assists users in managing and generating public opinion reports or related material through an automatic digest, document management, and report templates.

Network public opinion monitoring, analysis, and management is usually a continuous, relatively cyclical process made up of gathering, preprocessing, monitoring, providing early warnings, analysis, guidance, and other functions. A new round of gathering can detect the consequences of the previous round and adjust analysis and guidance strategies for continuous analysis to resolve a public crisis [31].

\subsection{Application of monitoring, analysis, and management of network public opinion in China}

In recent years, with the increasing number of Internet public opinion events in China, the community has begun to pay attention to public opinion monitoring, analysis, and management. The monitoring, analysis, and management of public opinion through technical means are extremely important. There are various types of public opinion monitoring and analysis institutions, forming a pattern of five forces, namely the government, media, universities, software companies, and commercial public relations companies. Among these, organizations relying on mainstream media resources usually have strong professional human resources, media influence, and greater professional recognition, such as the People.cn public opinion monitoring room and Xinhuanet public opinion monitoring and analysis center. Professional software companies focusing on network public opinion usually use technical research and development as their primary support. In addition, they have relatively stable customers and provide them with a series of monitoring and analysis services. Examples of these companies are Beijing TRS Information Technology Co. Ltd., Xiamen Meiya Pico Information Co. Ltd., and Hunan Eefung Software Co. Ltd. Furthermore, universities and research institutions have established research organizations such as the Public Opinion Institute of Renmin University of
China and the Media and Public Opinion Center of Fudan University.

Regarding application, government and enterprises improve their network public perception and crisis management capacity by cooperating with public opinion agencies to buy systems or services. Most customers of network public opinion systems and services are government agencies, universities, or large enterprises. However, nowadays, even small and medium-sized enterprises or public figures are becoming public opinion customers to preserve their product marketing or for personal reputation reasons.

\section{Challenges and opportunities}

The development and application of big data analysis technology and intelligent computing now provides new opportunities for network public opinion monitoring, analysis, and management.

\subsection{Challenges}

With the popularity of network applications, especially the promotion of mobile communication, the role of traditional and new media in network public opinion is changing. New media applications are no longer limited to microblogs, WeChat, or mobile apps, but also include Zhihu, Guokr, Internet radio, webcasts, bullet screens, and other applications. These applications have become new ways to disseminate information. As such, the network community formed by new media communication channels has become an important driving force of public opinion. Internet users and various online communities are more likely to take advantage of networks for over-marketing or overpromotion purposes. On one hand, the success of the hype has to a certain extent revealed the sources of events related to fairness and justice and hatred of richness and corruption, nationalism, and other social mentalities, and can be used to guide and follow up governance. On the other, the interaction between general Internet users, intellectuals, old and new media, opinion leaders, and other forces in the process of hyping these events has introduced new problems to social governance. Specifically, in the network community, knowledge Q\&A community, and other online media, the content of most discussions is more in-depth and professional. The voices of Internet users and opinion leaders are relatively rational, speculative, and have heavy influence, pushing the development of network public opinion to the edge of control. For example, the indicators of the inter-provincial adjustment events of the 2016-college entrance examination led to Hubei, Jiangsu, and other candidates to a gathering of parents, and most Internet users in the online community participated in the discussion of fair education as well.

Furthermore, media integration and capital operation of the new media have emerged, bringing more uncertainties and 
challenges to network public opinion analysis and management, because of commercial interests. By using network transmission, institutions or individuals acting on their own interests can more easily access public opinion. As such, the effective management of public opinion will become increasingly difficult.

From a system and technology perspective of network public opinion monitoring, analysis, and management, the development of new network media, emergence of various online communities, and the participation of ordinary Internet users and opinion leaders will lead to the explosive growth of network public opinion data along with new difficulties and challenges. At the same time, online and offline interaction through different media and network channels, which enhance interaction frequency, will change network public opinion development and make it more complex. Consequently, the traditional monitoring and evaluation model may face the dilemma of data modeling or inaccuracy. Thus, how to use computer science, network technique, big data analysis technology, as well as the new theories and methods of social psychology, management, communication, and other related disciplines to better meet these challenges is important for network public opinion monitoring, analysis, and management.

\subsection{Opportunities}

Big data analysis technology and intelligent computing development and application now provide new opportunities for network public opinion monitoring, analysis, and management.

The support of a big data cross-disciplinary analysis will expand the field of network public opinion monitoring, analysis, and management. Online and offline linkages and coordination of co-governance and cross-disciplinary analysis will also be further developed. Furthermore, the level of social innovation management will need to be improved. Based on the idea and technology of big data analysis, network public opinion data of different network channels are collected and merged, which is more likely to obtain accurate analysis results than that gained from a single channel. Specifically, big data and deep learning technology have recently been used in network public opinion analysis related to the analyses of text content and sentiment, obtaining good results. For example, for text analysis, results based on the convolutional neural network (CNN) [32] have been superior to those obtained through other models such as BM25 and ULM. To model the context of long sentences and documents, many scholars use a recurrent neural network (RNN), the long short term memory (LSTM) network, and bidirectional long short term memory network (BLSTM) to analyze the semantic association of context in text $[33,34]$ to achieve better results. Regarding sentiment analysis, the use of CNN to extract text features and the use of the model's hidden layer results for professional classifiers increased the positive/negative emotional attribute classification of a single statement from $80 \%$ to $85.4 \%$, while the precision of the fine-grained sentiment label reached $80.7 \%$ [35].

Based on this, combining big data and intelligent computing technology is expected to improve the prediction ability of network public opinion events. The development of big data technology has promoted changes in network public opinion monitoring, analysis, and management from qualitative management to quantitative calculation. As much as possible, information such as Internet users' comments, mood changes, and social relations are transformed into quantitative analysis data. Deep learning and other intelligent computing technology can dramatically improve the accuracy of network public opinion analysis. The above quantitative computing framework increases the accuracy of major public opinion events and expands the scope of research and evaluation of overall trends. Based on a crossdisciplinary analysis and more accurate quantitative analysis, the analysis and management of public opinion is expected to move from local passive response to global active reaction.

In addition, learning from international experience in network public opinion monitoring, analysis, and management is the way forward to comprehensive management and development. For example, the play of civil society and other social supervision forces and Internet users' self-discipline and other ways to analyze and manage cyberspace content will help reduce costs and improve the efficiency of public opinion management.

\section{Conclusions}

The arrival of the era of big data has brought about many challenges in the dissemination of channels, speed of transmission, data volume, data complexity, and public opinion management. Fortunately, it has also given rise to big data parallel processing, intelligent computing technology, and other possibilities of change and innovation. Future development strategy is rooted in the use of a big data and intelligent computing approach to solve the problems brought about by big data and the Internet. Based on in-depth research on new media communication and large-scale parallel computing and intelligent computing methods, the accuracy of public opinion prediction and the promotion of network public opinion management can be improved At the same time, based on existing methods and technologies, legal and civil government mechanisms should be employed to improve the efficiency of network public opinion analysis and management.

\section{References}

[1] China Internet Network Information Center. The 38th statistical report on Internet development in China [EB/OL]. (2016-08- 03) [2016-10-08]. http://www.cnnic.net.cn/hlwfzyj/hlwxzbg/ hlwtjbg/201608/t20160803_54392.htm. Chinese.

[2] Fang F J. Study on the evolution of public opinion on network of 
unexpected event [D]. Wuhan: Huazhong University of Science and Technology (Doctoral dissertation), 2011. Chinese.

[3] Sunstein C. Network republic: the problem of democracy in network society [M]. Huang W M. Shanghai: Shanghai People's Publishing House, 2003. Chinese.

[4] Bond R M, Fariss C J, Jones J J, et al. A 61-million-person experiment in social influence and political mobilization [J]. Nature, 2012, 489 (7415): 295-298.

[5] Kuhnen C M, Niessen A. Public opinion and executive compensation [J]. Management Science, 2012, 58 (7): 1249-1272.

[6] Chinese cyberspace Research Institute. Overseas Internet bad information supervision [M]. Beijing: Law Press, 2016. Chinese.

[7] Zhang Y W. Research on the mechanism of public opinion on Internet for unexpected emergency [D]. Beijing: Beijing University of Posts and Telecommunications (Doctoral dissertation), 2012. Chinese.

[8] Zhang Q. Ecological Governance of online public opinions and reconstruction of government trust [J]. Chinese Public Administration, 2014, 4: 10. Chinese.

[9] Wang P, Xie Y G. Study on the formation and evolution mechanism of public opinion in public emergency network [J]. Journal of Communication University of China, 2013 (3): 63-69. Chinese.

[10] Jin X, Xie B, Zhu J M. Micro-blog network public opinion dissemination based on complex network analysis [J]. Journal of Jilin University: Engineering Science, 2012 (S1): 271-275. Chinese.

[11] Liu J, Cai S Q. Research on characteristics of network public opinion communication of the micro-content [J]. Journal of Intelligence, 2013, 32 (1): 1-4. Chinese.

[12] Chen F J, Hu G L. On the spread pattern of network public opinion hot topics [J]. Journal of Intelligence, 2014, 33 (1): 97-101. Chinese.

[13] Zhu H M, Li Q, Research on the network public opinion communication model of micro-blog based on the topic derivative $[\mathrm{J}]$. New Technology of Library and Information Service, 2012, 5: 60-64. Chinese.

[14] Chen F J, Chen T. Research on derivative effects of network public opinions based on SEIRS propagation model [J]. Journal of Intelligence, 2014, 33 (2): 108-113. Chinese.

[15] Hu Y L, Bai L, Zhang W M. OLDA-based method for online topic evolution in network public opinion analysis [J]. Journal of National University of Defense Technology, 2012, 34 (1): 150-154. Chinese.

[16] Huang W D, Chen L Y, Wu M R. Research on sentiment evaluation of online public opinion topic [J]. Journal of Intelligence, 2014, 33 (1): 102-107. Chinese.

[17] Chen F J, Huang J L. Herd instinct of the transmission of network public opinion based on evolutionary game $[\mathrm{J}]$. Journal of Intelligence, 2013, 32 (10): 1-5. Chinese.

[18] Liu J D, Liu Y M. Herd behavior in the dissemination of public opinion on the Internet based on evolutionary game model with incomplete information [J]. Journal of National University of Defense Technology, 2013, 35 (5): 96-101. Chinese.

[19] Xiao L Y, Qi J Y. On the evaluation system of the social influence of enterprise public opinion on Internet based on microblog [J]. Journal of Intelligence, 2013, 32 (5): 5-10. Chinese.
[20] Fang F J. On social effects of network public opinion of emergencies [J]. Journal of Intelligence, 2014, 33 (11): 14-17. Chinese.

[21] Wang Y C. Universities' network public opinion characteristics and guidance research under we media-Based on the perspective of inducement analysis of universities' network public opinion [J]. Journal of Beijing University of Posts and Telecommunications (Social Sciences Edition), 2013 (5): 1-6. Chinese.

[22] Chen Z X, Wang X Y, Sun L, et al. Social psychological attitudes and demands reflected in important public events on network-An analysis of 120 network public opinion cases appeared during 2007-2012 [J]. Journal of Intelligence, 2014, 33 (3): 101-106. Chinese.

[23] Di G Q, Zeng H Y, Le Z J, et al. System dynamics modeling and simulation of Internet public opinions events [J]. Journal of Intelligence, 2012, 31 (8): 12-20. Chinese.

[24] Zhu Y H, Guo S Y, Zhang C Q. A review on application of simulation method in network public opinion research [J]. Journal of Intelligence, 2013, 32 (10): 29-35. Chinese.

[25] Liu Y. Construction of early warning index system of network public opinion based on triangular fuzzy number [J]. Statistics and Decision, 2012 (2): 12-15. Chinese.

[26] Zhang Y L. Causes and control strategies to the network public opinion of emergencies: Psychological analysis of their subjects [J]. Journal of Intelligence, 2012, 31 (4): 54-57. Chinese.

[27] Wang G H, Feng W, Wang Y L. Research on response to public opinion based on the classification of network public opinion $[\mathrm{J}]$. Journal of Intelligence, 2013, 32 (5): 1-4. Chinese.

[28] Chang R. Research on the network public opinion of group events and its management pattern and mechanism [D]. Jilin: Jilin University (Doctoral dissertation), 2012. Chinese.

[29] Lan Y X, Zeng R X. Research of emergency network public opinion on propagation model and warning phase [J]. Journal of Intelligence, 2013, 32 (5): 16-19. Chinese.

[30] Ma L, The Research of the governance of emergency network public opinion [D]. Beijing: Beijing University of Posts and Telecommunications (Doctoral dissertation), 2010. Chinese.

[31] Zhang D D, Lin S. Internet public opinion monitoring, early warning and guidance technologies [J]. Computer \& Network, 2014, 40 (19): 70-73. Chinese.

[32] Shen Y, He X, Gao J, et al. Learning semantic representations using convolutional neural networks for web search[C]// Wonjae Lee, et al. Proceedings of the 23rd International Conference on World Wide Web. Seoul: ACM, 2014: 373-374.

[33] Wang P, Qian Y, Soong F K, et al. A unified tagging solution: Bidirectional LSTM recurrent neural network with word embedding [J]. arXiv preprint arXiv:1511.00215, 2015.

[34] Le P, Zuidema W. Compositional distributional semantics with long short term memory[J]. arXiv preprint arXiv:1503.02510, 2015.

[35] Poria S, Cambria E, Gelbukh A. Deep convolutional neural network textual features and multiple kernel learning for utterance-level multimodal sentiment analysis[C]// Daniele Pighin, et al. Proceedings of EMNLP. Lisbon: ACM, 2015: 2539-2544. 